\title{
O Estabelecimento da Atenção Conjunta em um Bebê com Deficiência Visual Severa
}

\author{
Katia Miguel Colus* \& Katia de Souza Amorim \\ Faculdade de Filosofia Ciências e Letras de Ribeirão Preto, Universidade de São Paulo, Ribeirão Preto, SP, Brasil
}

\begin{abstract}
RESUMO - Atenção conjunta é uma capacidade relacional triádica, estabelecida na interação bebê-parceiro-objeto. É verificada pela direção do olhar ao olhar/ação do outro, sendo relatada como atenção visual conjunta. Pergunta-se como seria estabelecida em crianças cegas ou com deficiências visuais. Assim, investigou-se se e como ocorreriam construção, estabelecimento e manutenção da atenção conjunta em bebê com deficiência visual. Conduziu-se um estudo de caso de um bebê (inicialmente com sete meses), com videogravações, por quatro meses, na residência. A análise foi microgenética. Verificou-se que a atenção conjunta estabeleceu-se, foi construída e se manteve a partir de pistas não visuais, como táteis, olfativas, hápticas e sonoras. Adicionalmente, a emoção foi elemento favorecedor da atenção conjunta.
\end{abstract}

PALAVRAS-CHAVE: atenção conjunta, bebê, deficiência visual severa

\section{Establishment of Joint Attention in a Baby with Severe Visual Impairment}

\begin{abstract}
Joint attention is considered a triadic relational capacity, established in interaction baby-object-partner. It is verified by the direction of the gaze to another's look / action, being reported as joint visual attention. One may wonder how it would be established in blind or visually impaired children. Thus, it was investigated, if and how would occur construction, establishment and maintenance of joint attention in a baby with severe visual impairment. It was conducted a case study of a baby (first seven months), with video recordings, in residence. The analysis was microgenetic. It was verified that joint attention is established and maintained from non-visual cues, like tactile, olfactory, haptic and audible. Emotion was element to facilitate joint attention.
\end{abstract}

KEYWORDS: joint attention, baby, severe visual impairment

A investigação de processos de desenvolvimento nos primeiros anos de vida tem focado uma ampla gama de competências, tais como a construção de relações afetivas, manifestações emocionais, aquisição da linguagem e recursos comunicativos, significação e interação. Entre esses processos - e contribuindo para constituí-los -, destaca-se a atenção (Perra \& Gattis, 2012) e, especificamente, a habilidade denominada de atenção conjunta.

Essa competência vem sendo investigada há décadas, sendo que, na década de 1980, Bruner (1983) já a discutia. A atenção conjunta se define como a ocorrência de comportamentos, como olhar na direção do olhar do outro, observar a face do outro e depois a um terceiro elemento, mostrar e compartilhar objetos com outros (Aquino \&
Salomão, 2009). É uma habilidade fundamentalmente triádica e configura-se na interação bebê-parceiro-objeto. Segundo Tomasello (2003), os comportamentos componentes da atenção conjunta são comunicativos, em que a criança tanto acompanha o adulto, como busca atrair a sua atenção para um evento externo a ambos. O adulto corresponderia ao compartilhamento da atividade, validando e recompensando afetivamente o comportamento atencional do bebê.

Ainda segundo Tomasello (2003), até os nove meses, os bebês estabelecem apenas interações diádicas. A atenção conjunta emergiria nessa idade, quando os bebês começam a realizar comportamentos que parecem indicar uma compreensão emergente do outro como agente intencional igual a si próprio, cujas relações com entidades externas

*E-mail:katia_colus@hotmail.com

- Submetido: 19/11/2014; Aceito: 02/12/2016. 
podem ser acompanhadas, dirigidas ou compartilhadas. Os bebês passariam, dessa forma, a ser capazes de estabelecer interações triadicamente.

Stern (1992) entrelaça o processo da atenção conjunta com o elemento gestual. Para ele, há o ato de seguir a linha de visão de outrem e o gesto de apontar, sendo que antes dos nove meses os bebês já mostram uma forma preliminar dessa competência, seguindo a linha de visão da mãe. Aos nove meses, os bebês não apenas seguem visualmente a direção do olhar/apontar, mas, após atingir o alvo, olham de volta para a mãe e parecem usar o feedback de seu rosto para confirmar se chegaram ao alvo desejado.

O gesto de apontar é visto por diferentes autores como ocorrendo no final do primeiro ano de vida - entre os nove e doze meses de vida (Camaioni, Aureli, Bellagamba, \& Fogel, 2003; Iverson, 2010, Tomasello, Carpenter, \& Liszkowski, 2007; Vallotton, 2011; Vallotton \& Ayoub, 2010). Como Leung e Rheingold (1981) relatam, o aparecimento desses processos se dá em torno do primeiro ano de vida e, nessa fase, os bebês já aprenderam a olhar para onde outros apontam e também que os outros irão olhar na direção de onde eles apontam.

Tomasello (2003) afirma que o ato de apontar para um objeto ou para alguém para compartilhar a atenção é um comportamento comunicativo exclusivamente humano. Nesse sentido, Bussab, Pedrosa e Carvalho (2007) afirmam que humanos têm como característica distintiva uma forma típica de compreensão do outro, sendo capazes de se colocar no lugar deste e de assumir a sua perspectiva de um modo particular: são capazes de gestos protodeclarativos, que indicam a capacidade de compartilhadores de atenção.

A atenção conjunta tem sido discutida como crucial ao desenvolvimento, pois possibilita não só o compartilhamento de informações, como proporciona ao bebê, através do contato visual, a percepção do estado emocional do parceiro de interação. Determinantes dessa habilidade têm sido analisados - como idade, personalidade e linguagem (Benigno \& Farrar, 2012); estudos têm analisado esse comportamento em bebês de diferentes culturas, considerando, inclusive, a intencionalidade da criança (Callaghan et al., 2011). Segundo Bussab et al. (2007), a percepção da intencionalidade do/ no outro promove o bebê a um estado interativo que lhe possibilita maior domínio da situação interativa ao ler, no rosto e na posição dos olhos do outro, intenções e emoções, adequando-se ou não a elas. Assim, a atenção conjunta promove o estabelecimento de um conjunto de dimensões básicas ao desenvolvimento da linguagem, além de participar de processos cognitivos, sociais e afetivos da criança, sendo considerada como condição sine qua non para a construção da cognição social infantil.

Para Tomasello (2003), a atenção conjunta depende de processos maturacionais do bebê, emergindo a partir dos nove meses de idade. Assim, o autor foca o desenvolvimento da atenção conjunta triádica, a partir da intersubjetividade secundária, quando haveria adaptações biológicas para habilidades de compreensão da ação intencional de coespecíficos e motivação para compartilhar intencionalidade com coespecíficos.

Em outra vertente, Sinha e Rodriguez (2008) afirmam que a não plausibilidade de engajamento neonatal a conteúdos de intenções mentais tem levado alguns desenvolvimentalistas a negar a significância da intersubjetividade primária e a focar na secundária como a aquisição decisiva no desenvolvimento da mente compartilhada. Segundo eles, isso tem feito com que pesquisadores desconsiderem aspectos coparticipativos sociais e culturais da construção da intersubjetividade do bebê, naturalizando a habilidade de atenção conjunta. Para Sinha e Rodriguez, aquela seria coconstruída intersubjetivamente entre os parceiros, desde o nascimento. Esses autores recusam, portanto, a proposição em que predominam aspectos internos do bebê para o afloramento da habilidade, discutindo sua constituição intersubjetivamente em uma estrutura de ação conjunta, a qual não se reduz a estados mentais individuais. De acordo com esses autores, não se lidaria com fatos psicológicos, neurológicos ou maturacionais: a atenção conjunta representaria um fato social.

Para Aquino e Salomão (2009), a atenção conjunta também se desenvolve a partir da intersubjetividade inerente às trocas interativas estabelecidas entre adulto e criança, em contexto sociocultural, enfatizando o papel do outro. De modo semelhante, Bosa (2002) discute a atenção conjunta a partir da intencionalidade e do papel dessa na comunicação, criticando a compreensão dessa habilidade como competência interna da criança e relativamente independente do contexto familiar.

Outra característica dos estudos sobre atenção conjunta é de que se tem marcadamente centrado o seu aspecto visual, chegando a ser denominada de atenção visual conjunta (Corkum \& Moore, 1998; Deak, Flom, \& Pick, 2000). Os estudos apontam para a importância crucial da visão na estruturação dos processos de desenvolvimento, o olhar ocupando lugar central na interação com o outro, na apreensão do mundo e na mediação do mundo pelo outro. Sobre crianças com deficiências ou distúrbios, começa-se a ter estudos que abordam a questão a partir de exames de neuroimagem, como em Vanderwert e Nelson (2014). Usualmente, porém, trata-se de crianças mais velhas e com diagnóstico de autismo (Bosa, 2002). Os casos de crianças com deficiência visual severa ou cegueira pouco têm sido investigados. Bigelow (2003), que apresenta estudo empírico que trata da atenção conjunta em relação à cegueira, afirma que essa habilidade é possível para a criança cega, acontecendo a partir de outras informações e modalidades sensoriais, manifestando-se em idade mais tardia do que para a criança vidente. Já Sousa, Bosa e Hugo (2005) fazem menção à exploração tátil dos objetos pelas crianças com deficiência visual, a partir do auxílio da mãe.

No entanto, estudos que enfoquem a construção (ou nãoconstrução) da atenção conjunta em bebês com deficiência visual severa ou cegueira se fazem importantes, ainda mais 
se for considerado o dado de Gilbert (2001), que afirma existirem um milhão e meio de crianças cegas no mundo, estando três quartos delas em países em desenvolvimento. Esse número impõe a discussão sobre se e como a atenção conjunta aconteceria nessas crianças.

Com essa questão em foco e tendo como fundamento teórico uma perspectiva histórico-cultural, desenvolveu-se uma pesquisa que partiu da hipótese de que a construção da atenção conjunta se faz dentro de processos biologicamente culturais. Isso significa que ela é relacional, situada e imersa em processos de intersubjetividade. Mais ainda, considerando a plasticidade humana, entende-se que, naquelas relações, diferentes percursos de desenvolvimento podem ser seguidos, percursos mesmo ligados a crianças com diferenças orgânicas, como a deficiência visual. Dessa maneira, essas crianças teriam a possibilidade de desenvolver a atenção conjunta a partir de outras formas de apreensão do mundo e do outro.
Assim, propôs-se investigar, por meio de um estudo de caso, como se dá, em interações contextualizadas, a construção, o estabelecimento e a manutenção da atenção conjunta em um bebê com deficiência visual severa. O objetivo deste estudo foi apreender se os adultos e bebês se utilizam de recursos perceptuais variados e integrados englobando os táteis (toque, contato com o corpo do outro, percepção da temperatura), auditivos (chocalhos, sons cotidianos), olfativos (cheiro materno, odor dos alimentos, cheiros familiares) e verbais (vozes e falas, outros sons e ruídos), na busca pela construção e manutenção da atenção conjunta. Como objetivos específicos, buscou-se verificar se a criança mais responde à ação do outro ou se ela também busca conquistar a atenção do outro e, em caso afirmativo, como o faz. O que se interroga é se e como a atenção conjunta é construída e mantida pelas partes envolvidas, mesmo em condições (a)d(i)versas (como a deficiência visual), nas relações estabelecidas em contexto familiar.

\section{MÉTODO}

A abordagem metodológica utilizada foi o estudo de caso (Yin, 2005). Este representa uma estratégia de investigação, particularmente quando a questão de pesquisa propõe a investigação de "como" determinado evento ocorre - neste caso, como se dá o estabelecimento, a construção e a manutenção da atenção conjunta em bebês cegos ou com deficiência visual severa. Essa definição metodológica deveu-se ainda aos pressupostos de base histórico-culturais, que colocam a meta de acessar os processos como marcados pela complexidade. $\mathrm{O}$ estudo deveria assim se dar de maneira a preservar as características significativas dos acontecimentos, dentro de seus contextos e relações. Finalmente, o estudo de caso foi escolhido por se entender que se parte de hipótese que caminha em sentido oposto ao de uma gama grande de autores da literatura, ao se afirmar que a atenção conjunta não se dá somente mediada pela visão. Em função disso, a pesquisa implica na realização de estudo exploratório e descritivo.

Vale dizer que, apesar de o estudo de caso trabalhar com poucos sujeitos, sua análise permite o relacionamento entre o singular e o universal. Como Von Simson (Apresentação verbal, 2009) afirma, ao tratar da memória individual, as vivências e experiências pessoais apresentam conteúdos do grupo social, elementos que circulam no imaginário social. Os casos não representam, assim, situações particulares somente. Estas dialogam com e estão imersas em uma série de elementos socioculturais e biológicos, que contribuem para circunscrever e delimitar os processos em análise, permitindo que, com cuidado, se vá além do próprio caso.

Para conduzir o estudo empírico, o projeto foi submetido e aprovado pelo Comitê de Ética em Pesquisa, seguindo-se rigorosamente os preceitos éticos que embasam as normas do Conselho Nacional de Saúde (CNS).

\section{Participantes}

Definiu-se que seria selecionado um bebê como sujeitofocal, que apresentasse cegueira ou deficiência visual severa, com idade entre 6 e 12 meses de vida. Essa faixa etária foi escolhida em função da referida revolução cognitiva, proposta por Tomasello (2003), a qual é entendida como ocorrendo por volta dos nove meses de vida, em cujo período se daria a emergência da atenção conjunta. Como critério de exclusão/inclusão, o bebê não deveria ter histórico de outras doenças prévias associadas ou outros quadros, sendo que o diagnóstico de deficiência visual congênita ou de perda da visão deveria ter sido dado nos primeiros dois ou três meses de vida.

Como a atenção conjunta tem caráter fundamentalmente relacional, não só os bebês, mas também os parceiros (pais e irmãos) se constituíram como sujeitos de pesquisa. Ainda, a presença do pesquisador nas interações também foi considerada, já que, como afirmam Amorim e RossettiFerreira (2008), o pesquisador faz parte da pesquisa, também participa dela.

O bebê Mariana (nome fictício) e sua família pertenciam às camadas médias da população. No primeiro encontro com a criança, Mariana contava com 7 meses e 04 dias e tinha 11 meses e 25 dias no último encontro. Os pais relataram que Mariana nasceu a termo, não se notando nenhuma dificuldade ou diferença. Era usualmente uma criança extremamente calma, com pouquíssimos episódios de choro, ficando sozinha em seu quarto e no berço por longos períodos de tempo. Alguns meses após o nascimento, foram diagnosticados aniridia ${ }^{1}$ congênita bilateral, além de

1 Segundo Bicas e Jorge (2007), aniridia é ausência de íris, sendo considerada uma forma de glaucoma secundário e causa fotofobia. 
catarata $^{2}$ congênita lenticone posterior bilateral e glaucoma ${ }^{3}$ congênito secundário bilateral. Ela também apresentava nistagmo ${ }^{4}$. A associação dessas dificuldades, bem como sua gravidade, fez com que seu diagnóstico inicial fosse de cegueira. Com isso, os pais foram orientados a tratá-la como tal. Em função de sua idade precoce, entretanto, a detecção do grau exato de comprometimentos mostrou-se relativamente difícil.

\section{Procedimentos de Coleta e Registro dos Dados}

Para a coleta de dados, optou-se pelas videogravações, para registro das interações ao longo do tempo. A videogravação tem sido considerada como um recurso importante, pois possibilita a preservação do fenômeno, permitindo a repetição da observação e mais tempo para reflexão, com enriquecimento da análise em foco (Carvalho et al., 1996).

As gravações ocorreram na residência da família, com isso, garantiu-se a possibilidade de encontro da criança com vários de seus parceiros interativos, que fazem parte do seu cotidiano e que nem sempre podem estar presentes no laboratório. Na casa, ainda tem-se acesso a sons, cheiros e objetos, que fazem sentido para os bebês e seus parceiros, tendo-se também acesso privilegiado à dinâmica familiar. Essa riqueza, própria da casa, reflete-se nos comportamentos e aquisições do bebê, como discutido por vários autores (Bigelow, 2003; Bruner, 1997; Cavalcante, 2003; Clark, 1978; Taylor, 2010; Thoman, 1979; Trevarthen \& Aitken, 2001), os quais destacam a necessidade de se considerar a realização de estudos que apreendam os processos de maneira situada, imersa em aspectos culturais e em que a criança seja tanto uma protagonista, quanto uma vítima, um agente, um cúmplice (Bruner,1997).

Para o estudo de caso de Mariana, o cronograma montado para os encontros foi para acontecerem quinzenalmente ao longo de três meses, cada dia de gravação durando cerca de 50 minutos, em ambiente delimitado pela família. Em alguns dias a gravação foi mais curta, pelo fato de a criança adormecer ou por haver interrupção por questões de saúde e consulta médica da criança. Isso resultou num banco de imagens de aproximadamente cinco horas.

\section{Análise dos Dados}

A análise dos episódios foi qualitativa. De acordo com Pedrosa e Carvalho (2005), à primeira vista, a análise qualitativa pode parecer mais fácil, menos exigente, mais fluida ou livre do que a análise quantitativa. No entanto, entende-se que ela exige um esforço maior de explicitação de critérios para preservar o rigor científico e para tornar possível o compartilhamento produtivo de seus procedimentos e de seus resultados.

Cada videogravação foi retomada de forma a se delinear os episódios interativos das crianças com seus familiares. Nesses, buscou-se identificar a presença de pistas perceptivas visuais, auditivas, táteis, olfativas ou gustativas e, ainda, se e como essas eram utilizadas pelos sujeitos em interação para iniciar, construir e manter a atenção conjunta, considerandose tanto o bebê como os parceiros como agentes do processo.

Para cada videogravação, cenas foram selecionadas de acordo com a existência daqueles indícios de construção da atenção conjunta e de pistas perceptuais neles presentes. Não se determinou um número específico de recortes e nem um intervalo de tempo específico para cada recorte. Observou-se também o contexto, as práticas discursivas (Spink, 1999), as informações veiculadas, a (in)existência de objetos e brinquedos, a presença ou não de outras pessoas durante as videogravações e sua movimentação na cena. Todos esses dados foram considerados aspectos relevantes de mediação cultural na relação com a criança (Sinha \& Rodriguez, 2008).

A análise dos episódios selecionados foi microgenética, objetivando-se ter uma exposição à dinâmica dos processos. Góes (2000) explica que essa abordagem decorre da tese de Vygotsky (1991), de que os processos humanos têm gênese nas relações com o outro e com a cultura e de que a constituição do funcionamento humano é socialmente mediada, as relações devendo ser investigadas ao se examinar o curso de ação do sujeito. Como Vygotsky (1991) afirma, o comportamento só pode ser compreendido como a história do comportamento.

\section{RESULTADOS E DISCUSSÃO}

Neste artigo, privilegiou-se a apresentação e discussão de três episódios videogravados de Mariana, aos 7 meses e 19 dias (episódios 1 e 2) e aos 9 meses e 14 dias (episódio

2 A catarata é uma opacificação parcial ou total do cristalino (Bicas \& Jorge, 2007).

3 Glaucoma é uma neuropatia óptica crônica progressiva, caracterizada por alterações típicas da cabeça do nervo óptico, acompanhadas do aumento da pressão intraocular (Bicas \& Jorge, 2007).

$4 \mathrm{O}$ nistagmo afeta a capacidade de se manter o foco visual (Bicas \& Jorge, 2007)
3). Inicialmente, cada episódio será descrito e discutido individualmente, depois será feita uma discussão articulada dos três episódios analisados.

\section{Episódio I}

Mariana (com 7 meses e 19 dias) e sua mãe estão na sala, no sofá. Mariana está deitada no colo da mãe, mamando em uma mamadeira. Quando Mariana acaba de mamar, a mãe segura a mamadeira pela base, coloca-a à frente do rosto 
da criança e fala, olhando para ela: "Ó que bonita essa mamadeira! Ó! Ó! O bichinho. Ó o bichinho, Mariana..." O bebê abre mais os olhos, leva a mão esquerda na direção da mamadeira, segura-a, puxa-a na direção de seu rosto e encosta a lateral da mamadeira na boca. A mão esquerda permanece na mamadeira, enquanto a mão direita está ao lado do corpo, aberta, de forma a encostar levemente os dedos na mamadeira e nos dedos da mãe. A mãe mexe a mão e faz uma leve pressão com a mamadeira sobre o nariz da criança, movendo a mamadeira para os lados. A mãe repete essa ação por três vezes e diz: "Cheira a mamadeira, cheira... Ai, que cheirosa... Ai, que cheirosa...". Os dedos da mão esquerda do bebê estão apoiados na mamadeira e na mão da mãe. Ao cabo de 50 segundos a mãe afasta a mamadeira da criança, tampa-a e a põe no sofá, longe e atrás de Mariana. Mariana mantém o rosto voltado para onde a mamadeira estava inicialmente.

Ao longo de todo o episódio, a mãe olha para o bebê. Este, também, mantém-se atento à mãe, com corpo e rosto voltados na direção da mãe. Os olhos da criança estão direcionados à mãe, embora não se fixem nela, devido ao nistagmo.

Discussão episódio 1. Destaque-se que, a despeito da idade do bebê ( 7 meses e 19 dias $)$ e de a criança ter uma grave deficiência visual, após terminar de dar mamadeira ao bebê, para atrair a atenção da criança ao objeto, a mãe mostra-o à Mariana, procurando atrai-la visualmente. A mãe fala o quanto a mamadeira é bonita e que tem bichinhos desenhados, dando ao bebê pistas visuais. Além disso, observa-se que também há estimulação tátil e olfativa, quando a mãe brinca com o bebê apoiando o corpo da mamadeira no nariz da filha e, também, ao lhe dizer o quanto a mamadeira é cheirosa, deixando a criança tocar a mamadeira com seus dedos. Existe uma atmosfera de afeto conectora entre o bebê e a mãe, favorecendo e mantendo o engajamento.

À análise, observam-se comportamentos comunicativos, particularmente emitidos pela mãe, através dos quais a criança é chamada a acompanhar o outro em relação a um terceiro elemento - a mamadeira. Na interação, a díade busca estabelecer triadicamente as interações, compartilhando informações (Bussab et al., 2007; Tomasello, 2003), resgatando a beleza dos desenhos, o odor agradável, o formato e a textura da mamadeira. Esses comportamentos não se dão, como descrito na literatura, guiados pela direção do olhar ou por gestos (Stern, 1992; Tomasello, 2003).

Curioso é o quanto - apesar da deficiência da criança - a mãe destaca a apresentação de elementos visuais. Esse comportamento da mãe pode derivar do valor que é socialmente atribuído ao papel da visão ao desenvolvimento e à apreensão de mundo. Na própria literatura específica é dado destaque à visão, o processo sendo denominado por alguns autores de atenção "visual" conjunta (Corkum \& Moore, 1998; Deak et al., 2000).

Nesse caso, porém, em função da deficiência visual, o compartilhamento de informações não se faz através da visão. A criança deve ter outras possibilidades de perceber o estado emocional do parceiro de interação, de modo a coparticipar na modulação do contato e de forma a ter maior domínio de participação da situação interativa (Bussab et al., 2007). Assim, a despeito da idade do bebê (7 meses e 19 dias) e de a criança ter uma grave deficiência visual, Mariana mostra-se focada na relação mãe-objeto, seu corpo todo estando tensionado, direcionado e focado no que a mãe lhe apresenta, estabelecendo a triangulação da relação. O bebê apresentou a habilidade de atenção conjunta em idade anterior àquela proposta na literatura para crianças videntes, o que se contrapõe a resultados de pesquisas de autores que Bigelow (2003) descreve.

O que também se evidencia no episódio é o quanto cada um dos dois parceiros requer, diversamente, de certa extensão de tempo para apreensão de características dos objetos e de pistas dos mesmos. A mãe apresenta a mamadeira, mas de forma fugaz. Com isso, o bebê - mesmo capturado em sua atenção - fica com pouco tempo hábil para o envolvimento com o objeto, já que logo a mãe muda a posição da mamadeira e a faceta que destaca da mesma (cheiro, toque, sabor). Como Bigelow (2003, p. 261) afirma, o bebê cego tem necessidade de dispender mais tempo para a apreensão dos objetos, assim como uma dependência maior do adulto na apresentação desses, pois informações e eventos que ocorrem ao redor da criança cega precisam ser sequencialmente apresentadas, sintetizadas e reconstruídas, para que ela possa usar todo o seu corpo para obter informações sobre os objetos e explorá-los.

Em síntese, a mãe de Mariana se utiliza de várias pistas sensoriais e Mariana é receptiva a elas, havendo um aparente compartilhamento de informações numa triangulação da relação. Mesmo com a fugacidade referida, notam-se indícios de atenção conjunta.

\section{Episódio 2}

Mariana ( 7 meses e 19 dias), sua irmã de dois anos e sua mãe estão no chão da sala. A mãe e a irmã de Mariana estão sentadas frente a frente e se encontram brincando com um jogo de encaixar pequenas figuras coloridas de animais de e.v.a., em um tabuleiro vazado. Mariana está deitada de bruços, ao lado da mãe e da irmã. Em certo momento, a mãe mostra ao bebê um coelhinho verde do jogo. A mãe passeia com a peça em frente ao rosto de Mariana, dizendo, com voz modulada: "Ó... Olha, filha ... olha, filha, olha..." A mãe toca de leve com o objeto na mão esquerda do bebê e, nesse momento, Mariana segue com o corpo o movimento da mão da mãe. Essa ainda segura a peça do jogo e faz um movimento da mão em direção à esquerda da criança. Nesse momento, Mariana perde o foco do olhar na peça. Mariana vocaliza gritinhos: "Ahhhh...", continuando atenta e responsiva à situação. A mãe volta a sustentar a peça de maneira próxima ao rosto de Mariana. O bebê leva suas mãos na direção do mesmo e pega a peça entre os dedos da mão direita. Porém, a 
mãe continua segurando a peça em sua mão. Mariana afasta a sua mão direita da mão da mãe e agarra a mão da mãe com a sua mão esquerda. A mãe diz, com voz modulada: "Olha filha, olha...é o coelhinho, Mariana!', novamente, passando a peça próxima ao rosto do bebê e encostando-a suavemente no nariz da criança. O bebê vocaliza mais baixo e mais longamente "Ahhhhhh...". A mãe beija a mão esquerda de Mariana e retira sua própria mão, deixando Mariana pegar o coelhinho. Mariana fica segurando a peça de coelhinho com a mão direita e a encosta na boca. O bebê tira a mão da boca, estica o braço direito para o lado e traz de novo a peça para a boca. A mãe diz "E aí, cê tá chupando tudinho os bichinhos?" Então, a mãe se levanta, passa ao lado de Mariana e se dirige a outro cômodo. Enquanto isso, Mariana segura a peça com a mão direita, põe na boca, passa a peça para a mão esquerda e a mantém em frente à boca. Segura a peça, ainda na boca, com as duas mãos. Pouco depois, a mãe retorna à sala, aproxima-se da filha e a vira, deitando-a de costas. Oferece, então, à criança outra peça de e.v.a. do jogo. Mostra a peça ao bebê, conversando com ela e encostando-a em sua mão. Mariana tem sua atenção capturada e todo o seu corpo está voltado à mãe.

Discussão episódio 2. Apesar da idade da criança e de sua deficiência visual, há, nesse episódio, indícios de estabelecimento de atenção conjunta. A proposta de brincadeira para o bebê - apresentação de um coelhinho de e.v.a.- e direcionamento da atenção a um terceiro elemento foi feita pela mãe e se reveste de uma atmosfera carinhosa. Porém, novamente, o objeto não é destacado pelo olhar da mãe nem por gestos de apontar em direção a ele, apesar de lhe ser apresentado visualmente, passando o boneco à frente do rosto da criança. Há estímulos táteis (em que a mãe destaca o objeto através do toque do mesmo na mão da criança) e auditivos (através da fala da mãe, apesar de ser escassa a verbalização). Com esses comportamentos comunicativos, a mediação da mãe promove o foco da interação direcionado para o objeto. Ele se torna diádico (bebê-objeto), no entanto, quando há o afastamento da mãe, que sai do ambiente onde as duas se encontravam.

A peça de e.v.a. representa um brinquedo, um instrumento que a mãe oferece à criança, promovendo o ingresso ou a participação da criança em um mundo de significados previamente construídos socioculturalmente. Nesse sentido, Sinha e Rodriguez (2008) afirmam que os objetos se tornam para a criança representações materiais e significadores das regras, normas, valores, rituais, necessidades e objetivos dentro da matriz em que se inserem. É dessa maneira que vão se constituindo em construtores da intersubjetividade existente na interação. Através da relação que os parceiros estabelecem entre si a partir dos objetos, relação expressa primariamente pela corporeidade (Amorim \& RossettiFerreira, 2008) de ambos, é que parece ir se desdobrando a intersubjetividade.

Esse processo de mediação, de desdobramento da intersubjetividade e de construção e manutenção da atenção conjunta efetiva-se na relação, apesar de se dar novamente marcado pela fugacidade. O tempo de destaque ao terceiro elemento e os recursos pelos quais se busca despertar e efetivar a interação com o mesmo (predominantemente a visão) não permitem uma maior exploração triádica pela criança. Para a criança cega, a fugacidade presente em alguns momentos interativos, característica de uma abordagem sensorial típica do vidente, parece ser um complicador na construção do processo de atenção compartilhada.

\section{Episódio 3}

Mariana está com 9 meses e 14 dias e a cena se dá no consultório da terapeuta ocupacional (TO) que a acompanha. Na cena, Mariana e a TO estão sentadas sobre um colchonete, uma de frente para a outra. Sobre o colchonete há um pano preto com bolinhas brancas. O bebê está com a cabeça voltada para baixo na direção do pano. Ele segura o pano com as duas mãos, puxando-o e o esticando. Segurando-o com a mão direita, o bebê leva-o à boca. A mão esquerda está abaixada, tocando a parte do pano que está sobre o colchonete. $\mathrm{O}$ bebê está de cabeça baixa, voltada para o pano. A TO puxa, então, o pano delicadamente, enquanto vai falando com Mariana: “Ó ó ó...ó óó... será que você vai ficar brava comigo?'. Mariana solta o pano da mão esquerda e também da boca e apoia a mão esquerda no colchonete. A TO puxa o pano com a mão direita, olhando para o bebê. O pano fica esticado. O bebê o segura firme com a mão direita. Mariana apruma o corpo. Dirige o rosto para frente e abre mais os olhos. A TO diz: "Vamos ver.. vamos ver, Mariana. Aqui. Meu Deus do céu, não solta!” A TO ri e olha para Mariana. Mariana continua segurando o pano com a mão direita, a mão esquerda ficando apoiada no colchonete. Mariana apruma o corpo e vocaliza “Ahn...ahn..." Seu tom de voz e expressão facial, com a boca um pouquinho repuxada, sugerem irritação. $\mathrm{O}$ bebê continua segurando o pano com a mão direita e o movimenta, para cima e para baixo. Mariana abaixa o corpo e continua a movimentar o tecido para os lados, para cima e para baixo. Mariana pega o pano com a mão esquerda também, abaixa-se e tenta colocar o pano novamente na boca. A TO olha para o bebê e fala: "Fala assim: eu luto pelo que eu quero. É!" Mariana solta a mão direita do pano, puxa-o com a mão esquerda para o lado esquerdo. Mariana vocaliza "Ahn...". O bebê abaixase, põe o pano na boca, segurando-o com a mão direita levantada e com a mão esquerda apoiada no colchonete. A TO fala olhando para o bebê: "É! Tá pensando o quê? Que vai tirando o meu pano assim, sem me consultar?". O pano escapa da boca de Mariana, com um estalo. Mariana vocaliza: “Ahn!'”. Está absorta no pano, com o rosto voltado para ele. A TO olha para Mariana e diz: "Nossa Senhora, parece que eu vi um dentinho aí." Mariana puxa o pano com as duas mãos. Segura com a mão esquerda e com a mão direita põe o pano na boca. A TO solta o pano. Mariana dá um puxão maior no pano, com a mão esquerda. Com a mão 
direita, o bebê estica o pano, no colchonete, em seu redor. Mariana vocaliza: “Ahn...”. Ela está atenta ao pano, com o rosto voltado para ele. A TO olha para o bebê e fala: " $E$ muito legal tudo isso, né?!" Mariana vocaliza: "Ahn...”. A TO diz: "Você gosta? Esse pano ai é muito gostoso." Mariana continua manipulando o pano, com as duas mãos.

Discussão episódio 3. Esse episódio demonstra que a atenção conjunta de Mariana e da TO se estabeleceu e se manteve em relação ao tecido (terceiro elemento na relação), através de diversas modalidades perceptuais. Essas incluem, mas estão para além da visão (do tecido preto de bolinhas brancas), havendo elementos auditivos e vocais (fala da TO e balbucio do bebê), táteis, gustativos (quando a criança leva o pano à boca) e cinestésicos (tensão do tecido construída pelo puxar suavemente do pano entre as duas). Em termos de elementos visuais, Mariana tem sua atenção atraída pela TO a um objeto, através de uso de tecido reconhecidamente no campo das patologias visuais como atrativo (contraste de bolas entre as cores pretas e brancas).

Mariana mostra, através de seu corpo, o quanto está engajada na interação e tem interesse pelo jogo apresentado. Ela, a TO e o tecido são partes de um todo em que a ação e a atenção conjuntas ocorrem inseridas em um movimento que gera uma tensão entre ambas e o objeto, fazendo com que o bebê se mantenha engajado durante todo o tempo do recorte. Sinha e Rodriguez (2008) explicam que, na infância, o corpo não é o veículo ou o meio através do qual o engajamento ocorre, o corpo é o próprio engajamento.

Nesse episódio, a fala da TO com o bebê é decisiva na criação de um clima emocional positivo que favorece a conexão entre ambas. Existe um diálogo, criado não só pela fala da TO, mas também pelas verbalizações expressivas de Mariana, além dos corpos de ambas, através dos quais se desenrola a ação. Leiman (2002) afirma que, mesmo situações não estruturadas verbalmente, como gestos ou expressões faciais e corporais são capazes de propiciar mediação e fundamentar um diálogo.

No episódio, a atenção conjunta está plenamente estabelecida e mantida, de acordo com a idade preconizada por Tomasello (2003), não se sustentando o apontado por Bigelow (2003, pp.260-261), de que a criança cega pode demorar mais do que a criança que enxerga para a consolidação da habilidade de atenção conjunta. Sua apreensão pode não ser reconhecida, no entanto, já que o modo tradicional como a literatura discute tal processo, destaca-se que ele deveria se dar por mecanismos regidos pelo olhar.

\section{DISCUSSÃO GERAL}

Algumas considerações se impõem quanto ao estabelecimento e à manutenção da atenção conjunta para Mariana. Nos episódios selecionados, a atenção conjunta parece ser possível de se concretizar e de se manter, a partir de outras pistas perceptuais que não as visuais. Percepções auditivas, olfativas, táteis e cinestésicas mostraram-se eficazes na construção do estabelecimento da atenção conjunta em relações triádicas, a despeito dos limites existentes a partir das pistas visuais. A habilidade de atenção conjunta é discutida por muitos autores, como condição sine que non para o adequado desenvolvimento do bebê. Mariana demonstra ter condições de utilizar outros recursos de seu aparato perceptual para se orientar no sentido dessa aquisição, superando a prerrogativa eminentemente visual que tem sido imputada à atenção conjunta. $\mathrm{O}$ problema é $\mathrm{o}$ quanto a mediação por elementos visuais não é descartada pelos adultos ao redor, mesmo sabendo-se de uma deficiência visual por parte da criança.

Nos episódios selecionados, o envolvimento afetivo percebido através da responsividade na expressão facial dos parceiros e da receptividade percebida no rosto e no corpo de Mariana - também mostrou contribuir para o engajamento entre os parceiros e, consequentemente, o estabelecimento e a manutenção da atenção conjunta. Também, a idade de estabelecimento da atenção conjunta, para Mariana, parece estar de acordo com as descrições da literatura específica. Como referido anteriormente, não se confirma, neste trabalho, o apontado por Bigelow (2003, pp.260-261), de que a criança cega demore mais do que a criança que enxerga para a consolidação dessa habilidade.

O papel de mediador do adulto se evidencia nos episódios selecionados. No primeiro deles, torna-se bastante clara a necessidade de que o parceiro (no caso, um adulto) medie a relação do bebê com o objeto a ser apreendido, assim como também acontece para o bebê com desenvolvimento típico. Esse episódio possibilita algumas considerações a respeito não só da apropriação de informações sobre objetos por parte do bebê, mas também do papel do adulto nessa interação.

No primeiro episódio, Mariana está mamando no colo de sua mãe. Através das ações da mãe, são fornecidas ao bebê pistas perceptivas visuais (mamadeira perto do rosto), táteis (toque da mamadeira na mão e no nariz), auditivas (fala da mãe), olfativas (menção ao cheiro) e cinestésicas (posição). A mãe destaca algumas das pistas visuais, enquanto o bebê reage de modo mais evidente a outras pistas. Apesar das discrepâncias, o episódio revela indícios de direcionamento da criança em direção ao objeto apresentado pela mãe, constituindo a atenção conjunta. Apesar da riqueza de obtenção de informações que isso poderia proporcionar, parece que a mediação, os elementos mediados e a fugacidade como as pistas lhe foram oferecidas abreviam a capacidade de permanência da atenção ao terceiro elemento.

Infere-se que a brevidade de apresentação de cada situação possa dificultar a focalização num objeto externo à díade e à apreensão do outro e do mundo ao redor. Através da discussão de trabalho de Ochaita e Rosa (1995), Batista 
(2005) explica que a captação da informação mediante o tato é muito mais lenta que a proporcionada pelo sistema visual e tem caráter sequencial. Bigelow (2003) também afirma que informações sobre o espaço ao redor da criança e sobre os eventos que ali ocorrem devem ser sequencialmente explorados, sintetizados e reconstruídos pela criança cega. É preciso que, além de proporcionar diferentes percepções que oferecem informações sobre os objetos, pessoas ou eventos, haja maior tempo para experienciá-las e a possibilidade de integração dessas, propiciando-se à criança sua elaboração. Isso faz com que ela necessite de um tempo maior na manipulação do objeto, de forma a estimular o seu sistema háptico ou tato ativo, considerado o sistema sensorial mais importante para a pessoa cega.

Pode-se dizer que fica enfatizada a dependência do bebê com deficiência visual severa (assim como do bebê vidente também) em relação ao adulto, como mediador dessas informações. É a partir do corpo do adulto em relação ao seu próprio e das práticas discursivas presentes do parceiro de interação (neste recorte, a mãe) que essas informações adquirem significado. Pela linguagem verbal, ainda através do uso de palavras, remete-se a conceitos que vão sendo formados, relativos a objetos, situações e pessoas. É nesse processo interativo que as informações são social e historicamente conceitualizadas e contextualizadas.

No segundo episódio, evidencia-se novamente o papel do outro como propiciador de interação. Mariana estava deitada de bruços, muito próxima à mãe e à irmã, que jogavam um jogo de encaixe. Carinhosamente, a mãe lhe oferece uma peça do jogo, a que Mariana pega, mostrando ter tido sua atenção capturada por um terceiro objeto, na relação com a mãe. Para isso, a mãe se utilizou de pistas perceptivas visuais, táteis e auditivas e essas foram eficazes na constituição do estabelecimento da atenção conjunta. A manutenção dessa se dá pelo fato de que a mãe não solta a peça ao tocar o rosto de Mariana e nem quando Mariana a toca, garantindo a triangulação da relação. Apesar disso, logo em seguida e rapidamente a mãe se afasta.

Dois apontamentos são relevantes aqui: a importância da presença efetiva do adulto (ou parceiro mais habilitado) na interação, inserindo-se como parceiro na coconstrução dessa relação, como já discutido anteriormente. Destaca-se, além disso, a importância do objeto/ brinquedo como instrumento possibilitador de apreensão da cultura familiar e da cultura mais ampla em que a criança está inserida.

$\mathrm{O}$ brinquedo faz com que os parceiros da brincadeira tenham acesso à cultura e, com isso, insere-se como elemento importante na interação, possibilitando que bebê e adulto (ou outro parceiro) signifiquem e ressignifiquem comportamentos, atitudes e os objetos em questão. A ausência do brinquedo para a criança cega ou com deficiência visual severa pode significar uma dificuldade adicional à aquisição dos modos de funcionamento da cultura, bem como indicar que uma importante via de acesso à interação pode estar sendo subaproveitada. $\mathrm{O}$ bebê pode estar distanciado de modos apropriados à sua idade de construção de significados, conceitos e conhecimentos e estar sendo pouco solicitado para interagir.

No terceiro episódio, percebe-se que a atenção conjunta está estabelecida e mantida. Pistas táteis, auditivas e cinestésicas são utilizadas com Mariana, que responde a elas e se engaja no processo interativo e a remetem a estabelecer uma relação triádica com o objeto, juntamente com o seu parceiro. Há também a pista visual, pois o pano utilizado para Mariana contrasta as cores pretas e brancas, considerado adequado à sua condição visual.

A aquisição da habilidade de atenção conjunta por Mariana vem demonstrar que existe, da parte desse bebê, uma gama eficaz de possibilidades, que vão além daquela que é unicamente visual. Isso leva a se propor formas e caminhos alternativos, a partir de diversas modalidades sensoriais, que não a visual, para o estabelecimento e a manutenção da atenção conjunta, somando-se possibilidades às que alguns autores vêm indicando (p. ex., Corkum \& Moore, 1998; Deak et al., 2000).

Akhtar e Gernsbacher (2007) referem que crianças e adultos atentam para objetos e eventos que eles ouvem, tocam e percebem por outros meios que não unicamente a modalidade visual. Também narram que existe uma tendência evidente nas pesquisas de se valorizar exageradamente o comportamento visual na aquisição da atenção conjunta. $\mathrm{O}$ fato de Mariana ter estabelecido a atenção conjunta a partir de outras modalidades sensoriais questiona a própria definição de atenção conjunta como atenção "visual" conjunta, desafiando a primazia da visão e sugerindo a necessidade de abertura de novos estudos nesse campo.

É importante lembrar que houve a aquisição da relação triádica, como propõe Tomasello (2003), apesar de o bebê contar com 9 meses e 14 dias no momento da videogravação desse último episódio e apesar de contar ainda com uma diferença orgânica relevante, a deficiência visual severa. Esse dado também sugere que alguns atrasos do desenvolvimento imputados como consequências da cegueira e da deficiência visual severa precisam ser questionados. Como já citado, autores como Sinha e Rodriguez (2008) sugerem a necessidade de se considerar a ação e a atenção conjunta como um fato social, ultrapassando a abordagem predominantemente biológico-maturacional. Para isso, torna-se necessário realizar uma análise relacional e contextual dos processos envolvidos.

No caso analisado, apesar dessa aquisição pela criança, a atenção conjunta desenrola-se somente a partir da ação inicial do parceiro. Predominantemente, a criança acompanha o outro, não se tendo verificado que a mesma busque atrair a atenção do adulto para um evento externo a ambos, aspecto também considerado de importância no desenvolvimento desse processo. $\mathrm{O}$ adulto envolvido, nesse caso, basicamente promoveu e não respondeu ao chamado da criança ao compartilhamento da atividade, validando e recompensando afetivamente o comportamento atencional do bebê. 
Também, não se verificou o que Stern (1992) destaca, especificamente o entrelaçamento do processo da atenção conjunta visual com o elemento gestual. No caso, como a criança não é capaz de seguir visualmente o gesto de apontar e a linha de visão de outrem, ela não é capaz de emitir gestos e olhares e de buscar feedback no rosto do parceiro. No entanto, o estado emocional não é apreendido apenas pelo olhar, devendo ser considerados outros percursos e modos de apreensão da emoção na relação da díade no momento da triangulação da atenção.

Goffman (1980, p.15), ao tratar do estigma, afirma que tendemos a inferir uma série de imperfeições a partir da imperfeição original. É possível, portanto, que, à criança com deficiência visual severa, outras dificuldades sejam imputadas pela perspectiva vidente com a qual ela é encarada, inclusive em pesquisas sobre seu desenvolvimento. Dessa maneira, percalços e atrasos desenvolvimentais podem ser construídos pela perspectiva vidente de abordagem desse bebê e pelos métodos padronizados de pesquisas, que desconsideram o fluxo interativo cotidiano no/a partir do qual o desenvolvimento humano ocorre.

Assim, sugere-se que, a partir dos dados obtidos, possase considerar o estabelecimento da habilidade de atenção conjunta a partir de recursos perceptuais outros que estejam disponíveis ao bebê em seu percurso de desenvolvimento, não oferecendo à visão a primazia da apreensão e na conceituação do processo, visto que essa habilidade mostrou-se possível de ser constelada a partir de outras formas perceptuais. É importante que seja levado em conta o cenário em que permeiam as trocas intersubjetivas e que propiciam as interações entre os parceiros, desgarrando-se conceitualmente do paradigma dominante que encara a atenção conjunta como habilidade predominantemente biológico-maturacional.Com isso, propõe-se que se passe a contemplá-la como fato social, como proposto por Sinha e Rodriguez (2008).

Assim, sugere-se pensar na atenção conjunta como uma habilidade do bebê, que se traduz na ocorrência de comportamentos como seguir o foco atencional triádico, a partir das modalidades sensoriais disponíveis para esse bebê, sem priorizar essa ou aquela fonte de apreensão sensorial ou a idade do bebê como situação biológica demarcatória do surgimento da habilidade, abrangendo-se também a gênese do processo interativo subjacente, seus aspectos culturais e as características orgânico-sociais dos sujeitos nele envolvidos.

Para que se aprimore essa nova elaboração conceitual, sugere-se a realização de novos estudos, de forma a ampliar o número e o aprofundamento de casos. Sugere-se ainda que se dedique à questão da construção da atenção conjunta, tanto para crianças com desenvolvimento típico quanto para aquelas diferentemente constituídas. O presente trabalho, ainda de forma incipiente, sugere e propõe esse novo percurso nessa área da psicologia do desenvolvimento.

\section{REFERÊNCIAS}

Akhtar, N., \& Gernsbacher, M. A. (2007). Joint attention and vocabulary development: A critical look. Language and Linguistic Compass, 1(3), 195-207. doi: 10.1111/j.1749818x.2007.00014.x .

Amorim, K. S., \& Rossetti-Ferreira, M. C. (2008). Dialogismo e a investigação de processos desenvolvimentais humanos. Paidéia, 18(40), 235-250. doi: 10.1590/S0103-863X2008000200003.

Aquino, F. S. B., \& Salomão, N. M. R. (2009). Contribuições da habilidade de atenção conjunta para a habilidade social infantil. Psicologia em Estudo, 14(2), 233-241. Recuperado de http:// www.scielo.br/scielo.php?script $=$ sci_arttext\&pid $=$ S1413$73722009000200003 \& \operatorname{lng}=$ en $\& n r m=$ iso.

Batista, C. G. (2005). Formação de conceitos em crianças cegas: Questões teóricas e implicações educacionais. Psicologia: Teoria e Pesquisa, 21(1), 7-15. Recuperado de http://www. scielo.br/pdf/ptp/v21n1/a03v21n1

Benigno, J. P., \& Farrar, M. J. (2012). Determinants of joint attention in young siblings' play. Infant and Child Development, 21(2), 160-174.

Bicas, H. E. A., \& Jorge, A. A. H. (2007). Oftalmologia: Fundamentos e aplicações. São Paulo: Tecmedd Editora.

Bigelow, A. E. (2003). The development in joint attention in blind infants. Development and Psychopathology, 15(2), 259-275. doi: 10.1017/S0954579403000142.

Bosa, C. (2002). Atenção compartilhada e identificação precoce do autismo. Psicologia, Reflexão e Crítica, 15(1), 77-88. Recuperado de http://www.scielo.br/pdf/prc/v15n1/a10v15n1.

Bruner, J. (1983). Como as crianças aprendem a falar. Lisboa: Instituto Piaget.

Bruner, J. (1997). Atos de significação. Porto Alegre: Artes Médicas.
Bussab, V. S. R., Pedrosa, M. I. C., \& Carvalho, A. M. A. (2007). Encontros com o outro: empatia e intersubjetividade no primeiro ano de vida. Psicologia USP, 18(2), 99-133. Recuperado de http://www.scielo.br/scielo.php?script=sci arttext\&pid=S0103-65642007000200007\&lng=en\&tlng=pt. 10.1590/S0103-65642007000200007

Callaghan, T., Moll, H., Rakoczy, H., Warneken, F., Liszkowski, U., Behne, T., \& Tomasello, M. (2011). Early social cognition in three cultural contexts. Monographs of the Society for Research in Child Development, 76(2), 34-104.

Camaioni, L., Aureli, T., Bellagamba, F., \& Fogel, A. (2003). A longitudinal study examination of the transition to symbolic communication in the second year of life. Infant and Child Development, 12(2), 1-26. doi: 10.1002/icd.333

Carvalho, A. M. A., Bergamasco, N. H. P., Lyra, M. C. D. P., Pedrosa, M. I., Rubiano, M. R. B., Rossetti Ferreira, M. C. R. ... Vasconcellos, V. M. R. (1996). Registro em vídeo na pesquisa em psicologia: reflexões a partir de relatos de experiência. Psicologia: Teoria e Pesquisa, 12(3), 261-267.

Carvalho, A., \& Hamburger, A. I., \& Pedrosa, M. I. (1996). Interação, regulação e correlação no contexto do desenvolvimento humano: discussão conceitual e exemplos empíricos. Publicações IFUSP, 1196, 1- 34.

Cavalcante, M. C. B. (2003). O estatuto do manhês na aquisição da linguagem. DLCV Língua, Linguística e Literatura, 1(1), 147-156. Recuperado de http://periodicos.ufpb.br/ojs/index. $\mathrm{php} / \mathrm{dclv} / \mathrm{article} / \mathrm{view} / 7447$

Clark, R.A. (1978). The transition from action to gesture. In A. Lock (Ed.), Action, gesture and symbol: The emergence of language. London: Academic Press. 
Corkum, V., \& Moore, C. (1998). Origins of joint visual attention in infants. Developmental Psychology, 34(1), 28-38. doi: 10.1037/0012-1649.34.1.28.

Deak, G. O., \& Flom, R. A., \& Pick, A.D. (2000). Effects of gesture and target on 12-and 18-month-olds' joint visual attention to objects in front of or behind them. Developmental Psychology, 36(4), 511-523. doi:10.1037/0012-1649.36.4.511.

Gilbert, C. (2001). New issues in childhood blindness. Journal of Community Eye Health. 15(40), 2001, 53-56. Recuperado de http://www.v2020la.org/actionplan/documents/New\%20 issues $\% 20$ in $\% 20$ childhood $\% 20$ blindness.pdf

Góes, M.C.R. (2000). A abordagem microgenética na matriz histórico-cultural: Uma perspectiva para o estudo da constituição da subjetividade. Cadernos Cedes, 20(50), 9-25. Disponível em http://www.scielo.br/pdf/ccedes/v20n50/a02v2050

Goffman, E. (1980). Estigma. Notas sobre a manipulação da identidade deteriorada. Rio de Janeiro: Zahar Editores.

Iverson, J. M. (2010). Multimodality in infancy: Vocal-motor and speech-gesture coordinations in typical and atypical development. Enfance, 3, 257-274. doi : http://dx.doi. org/10.4074/S0013754510003046

Leiman, M. (2002). Toward Semiotic Dialogism: The role of sign mediation in the Dialogical Self. Theory \& Psychology, 12(2), 221-235. doi: 10.1177/0959354302012002631

Leung, E. H., \& Rheingold, H. L. (1981). Development of pointing as a social gesture. Developmental Psychology, 17(2), 215-220. doi: 10.1037/0012-1649.17.2.215

Ochaita, E., \& Rosa, A. (1995). Percepção, ação e conhecimento nas crianças cegas. In C. Coll, J. Palácio, \& A. Marchesi (Orgs.), Desenvolvimento psicológico e educação (vol.3, pp.183-197). Porto Alegre: Artes Médicas.

Pedrosa, M. I., \& Carvalho, A. M. A. (2005). Análise qualitativa de episódios de interação: Uma reflexão sobre procedimentos e formas de uso. Psicologia: Reflexão \& Crítica, 18(3), 431442. Recuperado de http://www.scielo.br/pdf/prc/v18n3/ a18v18n3.pdf

Perra, O., \& Gattis, M. (2012). Attention engagement in early infancy. Infant Behavior \& Development, 35(4), 635-644.

Sinha, C., \& Rodriguez, C. (2008). Language and the signifying object: From convention to imagination. In C. Sinha, J. Zlatev, E. Itkonen, \& T.P. Racine (Orgs.), The Shared Mind: Perspectives on intersubjectivity (pp. 357-378). Amsterdam: John Benjamins.

Sousa, A. D., Bosa, C. A., \& Hugo, C. N. (2005). As relações entre deficiência visual congênita, condutas do espectro do autismo e estilo materno de interação. Estudos em Psicologia, 22(4), 355-364. ISSN 0103-166X. doi: 10.1590/S0103166X2005000400003.

Spink, M. J. (1999). Práticas discursivas e produção de sentidos no cotidiano: Aproximações teóricas e metodológicas. São Paulo: Cortez Editora.

Stern, D. (1992). Diary of a Baby. New York: Basic Books.

Taylor, C. L. (2010). Early motor development is part of the resource mix for language acquisition - a commentary on Iverson's 'developing language in a developing body: the relationship between motor development and language development'. Journal of Child Language, 37, 281-285. doi: 10.1017/ S0305000909990468 281

Thoman, E. B. (1979). Changing views on the being and becoming of infants. In E. B. Thoman (Ed.), Origins of the infant's social responsiveness (pp. 445-459). New York: John Wiley Sons.

Tomasello, M. (2003). Origens culturais da aquisição do conhecimento humano. São Paulo: Martins Fontes.

Tomasello, M., Carpenter, M., \& Liszkowski, U. (2007). A new look at infant pointing. Child Development, 78(3), $705-722$. doi: $10.1111 / \mathrm{j} .1467-8624.2007 .01025 . \mathrm{x}$

Trevarthen, C., \& Aitken, K. J. (2001). Infant intersubjectivity: Research, theory and clinical applications. Journal of Child Psychology and Psychiatry, 42(1), 3-48. doi: 10.1111/14697610.00701

Vallotton, C. (2011). Babies open our minds to their minds: How listening to infant signs complements and extends our knowledge of infants and their development. Infant Mental Health Journal, 32(1), 115-133. Doi: 10.1002/imhj.20286

Vallotton, C. D., \& Ayoub, C. C. (2010). Symbols build communication and thought: The role of gestures and words in the development of engagement skills and social-emotional concepts during toddlerhood. Social Development, 19(3), 601-626. doi: 10.1111/j.1467-9507.2009.00549.x

Vanderwert, R. E., \& Nelson, C. A. (2014). The use of near infrared spectroscopy in the study of typical and atypical development. Neuroimage, 85, 264-271.

Von Simson, O. R. M. (2009). Memória, cultura e sociedade do esquecimento [Apresentação realizada na Semana da Psicologia da (FFCLRP)]. Universidade de São Paulo, Ribeirão Preto, SP, Brasil

Vygotsky, L. S. (1991). Pensamento e linguagem. São Paulo: Martins Fontes.

Yin, R. K. (2005). Estudo de caso. Planejamento e Métodos. Porto Alegre: Bookman. 


\section{ERRATA}

No artigo:

Colus, Katia Miguel. (2019). O Estabelecimento da Atenção Conjunta em um Bebê com Deficiência Visual Severa. Psicologia: Teoria e Pesquisa, 35, e3541. https://dx.doi.org/10.1590/0102.3772e3541

\section{Página 1,}

Onde se lê:

\section{Katia Miguel Colus*}

Faculdade de Filosofia Ciências e Letras de Ribeirão Preto, Universidade de São Paulo, Ribeirão Preto, SP, Brasil

\section{Leia-se:}

Katia Miguel Colus* \& Katia de Souza Amorim

Faculdade de Filosofia Ciências e Letras de Ribeirão Preto, Universidade de São Paulo, Ribeirão Preto, SP, Brasil 